\title{
Weather and climate socio-economic impacts in Central America for the management and protection of world heritage sites and the Diquis Delta culture in Costa Rica (a case study)
}

\author{
J. A. Amador ${ }^{1,2}$ and E. J. Alfaro ${ }^{1,2,3}$ \\ ${ }^{1}$ School of Physics, University of Costa Rica, 11501 San Jose, Costa Rica \\ ${ }^{2}$ Center for Geophysical Research, University of Costa Rica, 11501 San Jose, Costa Rica \\ ${ }^{3}$ Center for Research in Marine Sciences and Limnology, University of Costa Rica, 11501 San Jose, Costa Rica \\ Correspondence to: J. A. Amador (jorge.amador@ucr.ac.cr)
}

Received: 6 February 2013 - Revised: 24 July 2013 - Accepted: 4 December 2013 - Published: 10 January 2014

\begin{abstract}
The Central America region hosts a valuable amount of World Heritage Sites (WHS), many of them located in areas of floods, landslides, drought, high winds, intense precipitations, and earthquakes. The effective management of WHS requires the understanding of this type of environmental phenomena and their potential impacts on these sites. The objective of this work is twofold. To make an analysis of some of the atmospheric systems (easterly waves, cold fronts and tropical cyclones [TCs]) hitting Central America, to estimate their effects on socio-economic activities and potential impacts on WHS during the period 2002-2012. The second objective is to identify, for a case study, the potential effects of hydro-meteorological events associated with a tropical storm on the Diquis Delta region in southern Costa Rica. This site, an important unique archeological site of stone spheres, has been proposed by this country as a WHS. To achieve both, public data bases like HURDAT (North Atlantic Hurricane Database), and information from regional newspapers and National Emergency Committees, among other sources, were used for the study of socio-economic impacts caused by these natural hazards. To accomplish the latter, course resolution NCEP/NCAR (National Center for Environmental Prediction/National Center for Atmospheric Research) Reanalysis atmospheric data served to initialize version 5 of a numerical atmospheric mesoscale model (MM5). This approach permitted to obtain higher resolution gridded data for a set of atmospheric variables for a case study associated with the formation of tropical storm Alma upon the Pacific basin. The MM5 resulted winds and precipitation, among other variables, were
\end{abstract}

then used to evaluate potential impacts on the WHS region. Among the systems analyzed for Central America, TCs were the ones that most severely impacted regional social life and worsened the already weak regional economies. During the period analyzed, TCs affected regions where WHS are very relevant to cultural life and touristic income. The MM5 derived data shows its potential for providing detailed spacetime atmospheric data to help quantify and anticipate impacts for WHS protection and management. The overall results are expected to bring the attention of organizations and governments about the importance of socio-economic and cultural losses associated with the impacts caused by natural hazards near WHS in the region.

\section{Introduction}

Central America hosts a relatively high density of World Heritage Sites (WHS) in comparison to its geographical size; many of these sites are situated in areas of floods, drought, high winds and intense precipitations. This region has about 16 of these sites and 31 new proposals to UNESCO for World Heritage, tangible and intangible. Most of these places are vulnerable to volcanic and seismic actions, but are more often exposed to weather and climate impacts from both, the Caribbean and Pacific basins. The effective management and future protection of WHS requires understanding of the physical causes and the space-time evolution of this type of natural phenomena to take actions against their potential impacts. Two major objectives are here pursued. Firstly, to analyze 
some meteorological systems, such as cold fronts, easterly waves and tropical cyclones (TCs) hitting Central America, in order to estimate their potential effects on socio-economic activities upon the countries in the region that may prevent and/or reduce the government's investment in WHS management and protection. The second objective using a case study is to identify and understand potential impacts in a proposed WHS in the Diquis Delta in southern Costa Rica (Fig. 1). This region witnessed the flourishing of a unique archeological and cultural site associated with ancient stone spheres (Quintanilla and Badilla, 2001). To achieve the above objectives, historical data on some extreme climate events, such as floods and droughts associated with the above mentioned systems was collected to assess the socio-economic impacts in the region during the period 2002-2012. Socio-economic data on the proposed archaeological site of stone spheres in southern Costa Rica were gathered using an innovative approach. This entails the application of an atmospheric dynamical numerical model to increase the resolution of the atmospheric data (e.g. wind, precipitation, and temperature) over the region of the proposed WHS. The input for that model is courser resolution meteorological data on a larger space domain. The higher resolution data is expected to improve the understanding of sub-regional meteorological impacts under extreme conditions such as high winds, intense precipitation and floods induced by a tropical storm. This detailed information can help in the management and protection of sites of cultural interest at regional scale. To the author's knowledge, this is the first approach of its kind in the study of potential impacts on WHS by the use of atmospheric dynamical modeling.

This paper has been organized as follows. In the next section, the region of analysis, Central America, is presented; the main geographical and socio-economic characteristics are discussed, followed by a description of the relevant regional climate, to finish with a brief account of WHS in the region (provided for the sake of completeness), and a discussion about the importance of the Diquis Delta archeological site for social and cultural life in the region. The effect of climate impacts at regional scale is highlighted all along this section. The third section, dedicated to data and methods, gives information on climate data used to identify the regional meteorological systems that hit Central America in the period 2002-2012 for the analysis of socio-economic impacts. Section 3 also contains the historical and socioeconomic information sources to match the analysis done about the meteorological regional systems that impacted the region. At the end of this section, the methods of analysis are discussed, and a brief explanation of the numerical model used and the dynamical downscaling technique required to obtain high resolution atmospheric data is explained. Section 4 presents the results for the regional analysis, the socioeconomic impacts due to the atmospheric systems analyzed and the outcome of the numerical model application to the Diquis Delta archeological site, focusing on the potential

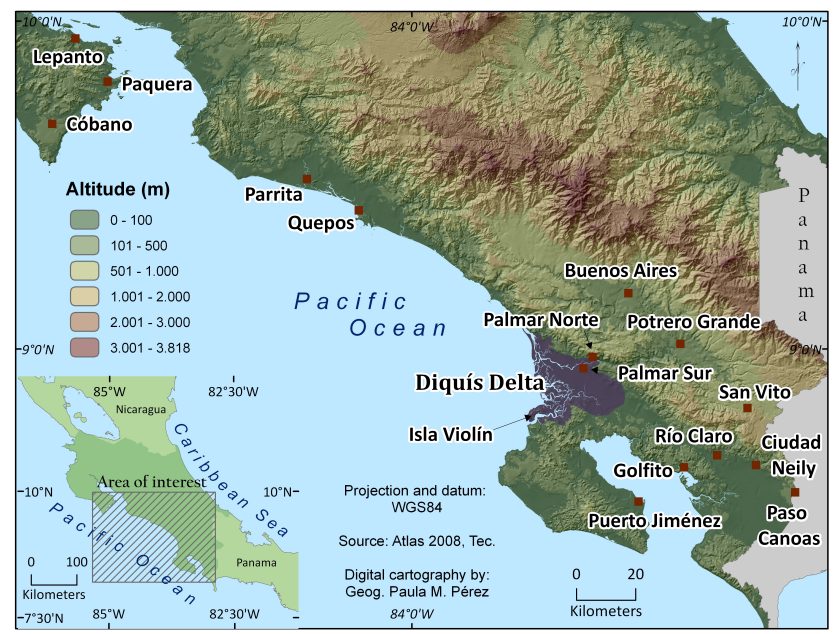

Fig. 1. Geography of the Pacific slope of southern and central Costa Rica showing the topography, the Diquis Delta (in purple), and some of the cities located in that region.

meteorological impacts upon this region. Finally, Sect. 5 is devoted to present the conclusions and some recommendations for future work to improve the management and protection of WHS in regard to weather and climate impacts.

\section{The region of analysis: Central America}

\subsection{Geography and socio-economics: a brief overview}

Central America is a relatively small bridge of land connecting the sub-continents of North and South America, with the Caribbean Sea (CS) to the east and the eastern tropical Pacific (ETP) to the west. The location and topographical characteristics of the Central America Isthmus in the Intra-Americas Seas (IAS), formed by the Gulf of Mexico, the Caribbean Sea, and the easternmost tropical Pacific, Central America, and northwestern South America, defines most of its climate and its climate variability. The region's climate is influenced by the physical interaction of a wide range of weather and climate systems at different time and space scales; from local to regional (easterly waves, cold fronts, tropical cyclones, among others) to global scale signals such as El Niño-Southern Oscillation (ENSO), and the America Monsoon System. The IAS, and as a consequence, Central America is one of the most impacted regions in the world in regard to tropical cyclone activity and other hydro-meteorological events (Alfaro and Quesada, 2010). Amador et al. (2010, 2012) and Amador (2011) reported major socio-economic losses due to some of these natural hazards in recent years. Although climate change impacts on this region may be severe in the future (Hidalgo et al., 2013), the consideration of this effect is well beyond the scope of this work

With an estimated population of about 45 million, some Central America countries maintain relatively weak 
economies (much of them based on agriculture and tourism, and some on external commerce, transport and services) in order to sustain relevant losses associated with weather and climate issues to keep up with required social life at minimum standards. According to the World Bank (http://data.worldbank.org/about/country-classifications/ country-and-lending-groups\#Low_income, last access: 21 July 2013) most countries in Central America are lower-middle-income economies (USD 1035 to 4085), except Belize, Costa Rica and Panama considered as upper-middle-income economies (USD 4086 to 12615). The socio-economic impacts of hydro-meteorological and climate events are then very important for these nations (see Amador et al., 2010; Amador, 2011), since they jeopardize the efforts toward social development and put at risk the preservation of its cultural roots and traditions, especially their WHS (see a complete list of sites at http://whc.unesco.org/en/list, last access: 21 July 2013).

\subsection{Summary of regional climate}

Among the climate hazards that affect the rich world heritage places of Central America are, the boreal winter cold front intrusions reaching low latitudes (also known as cold outbreaks or more locally as "Nortes" referring to the wind intensity associated with the fronts). During summer-autumn the region is affected by easterly waves and by the activity of two very active tropical cyclone regions, the AtlanticCaribbean and the Eastern Tropical Pacific. The IAS region is characterized by climate features of unique nature. The Mid-Summer Drought (MSD) or "veranillo" (in Spanish), an atmospheric attribute rarely observed in tropical regions (Magaña et al., 1999); the IAS or Caribbean low-level jet during summer (Amador, 1998) and its winter counterpart (Amador et al., 2006; Amador, 2008), a strong easterly current over the CS; the Caribbean and ETP warm pools where many tropical cyclones (TCs) form (Gray, 1979; Wang and Enfield, 2001, 2003); and the strong convective activity of the Inter Tropical Convergence Zone (ITCZ). All these atmospheric signals strongly impact social and economic life in the region (e.g. the MSD affects the agriculture sector, Magaña et al., 1999). Other details on socio-economic impacts caused by TCs activity can be found in Amador et al. (2010) and Amador (2011).

According to Alfaro (2000) and Taylor and Alfaro (2005), the tropical maritime location temperature changes throughout the region are generally small, and rainfall is by far the most important meteorological element. In general the climate of the region is controlled by the migration of synoptic features, and the mean climate strongly reflects the annual cycle of these systems. The most dominant synoptic influence is the subtropical high of the north Atlantic; others include: (a) the seasonal migration of the ITCZ, mainly affecting the Pacific side of Central America; (b) the "temporales", a period of weak-to-moderate nearly continuous rain, lasting several days and affecting a relatively large region (Hastenrath, 1991; Amador et al., 2003); and (c) westward propagating tropical disturbances, a summer-fall season feature associated with much rainfall especially over the Caribbean region.

Mean annual rainfall totals vary over a wide range in Central America, partly in response to the diversity of topographical features. Analysis of the mean annual cycle of precipitation reveals two dominant modes. On the Pacific slope, the first and more representative mode is characterized by two rainfall maxima in June and September-October, an extended dry season from November to May, and a shorter reduced precipitation period during July-August (MSD). This regime, except the MSD, is largely explained by the seasonal migration of the subtropical north Atlantic high and the ITCZ (Alfaro, 2002; Taylor and Alfaro, 2005).

The dry season of winter and early spring is more intense on the Pacific slope of the isthmus, possibly due to an additional drying effect caused by the seasonal reversal of the winds on the Pacific side which blow offshore during winter. The ITCZ is also at its maximum southeast position during February and March. The season is further characterized by strong Atlantic trades, high values of total radiation and sunshine hours in the low troposphere levels. The mean onset of the rainy season is in May. The latitudinal variation may be partially explained by the northward migration of the ITCZ that causes instability and humidity convergence in southern Central America from boreal late spring to early fall. The Caribbean coast exhibits a second rainfall mode, different from the dominant dry-winter/wet-summer regime. It is difficult to define a dry season for this region as rainfall is nearly homogeneous between January and the middle of October. From mid-October onwards there is a marked increase in precipitation accumulation until the end of the year, with a maximum at the beginning of December. This maximum could reflect the influence of cold fronts over the North-Caribbean Central American coast during boreal winter and/or the intensification of the winter trade winds which transport humidity and produce precipitation on the windward side. Significantly, there is no rainfall minimum in July, but instead a relative maximum characterizing the mode 2 region. This might result from the low-level jet influence and the interaction between topography and the low-level wind (Amador, 1998, 2008). Interestingly it is the same mechanism (i.e. the intensification of the trades) which both yields the MSD over most of Central America and makes the Caribbean slope wetter than the Pacific slope during July (Alfaro, 2002; Taylor and Alfaro, 2005).

\subsection{World Heritage Sites}

There are 16 UNESCO WHS in Central America. Some are, Belize Barrier Reef Reserve System (Belize), Antigua (Guatemala), Joya de Cerén Archeological Site (El Salvador), Maya Site of Copan (Honduras), Ruinas de Leon 
Table 1. World Heritage Sites in Central America impacted by environmental phenomena during 2008-2012 (last access: 21 July 2013).

\begin{tabular}{|c|c|c|c|}
\hline $\begin{array}{l}\text { Date } \\
(\mathrm{dd} / \mathrm{mm} / \mathrm{yyyy})\end{array}$ & WHS & $\begin{array}{l}\text { Socio-economic } \\
\text { impacts }\end{array}$ & Sources of information \\
\hline 8 Oct 2008 & Ruinas de Leon & $\begin{array}{l}\text { Floods, } 12 \text { deaths, } \\
4970 \text { people affected, } \\
921 \text { families in shelters }\end{array}$ & $\begin{array}{l}\text { Europapress, Spain } \\
\text { http://www.europapress.es/ }\end{array}$ \\
\hline 1 Apr 2011 & Antigua Guatemala & Floods & $\begin{array}{l}\text { El Metropolitano, Guatemala } \\
\text { http://antigua.elmetropolitano.com.gt/ }\end{array}$ \\
\hline 17 Oct 2011 & Joya del Ceren & Floods & $\begin{array}{l}\text { El Nuevo Diario, Nicaragua } \\
\text { http://impreso.elnuevodiario.com.ni/ }\end{array}$ \\
\hline 2 Jun 2012 & Antigua Guatemala & Floods and damaged roads & $\begin{array}{l}\text { Siglo 21, Guatemala } \\
\text { http://www.s21.com.gt/ }\end{array}$ \\
\hline 5 Aug 2012 & Panama Viejo & Floods, 402 people affected & $\begin{array}{l}\text { Panamerica, Panama } \\
\text { http://www.panamaamerica.com.pa/ }\end{array}$ \\
\hline 27 Sep 2012 & Panama Viejo & 60 families relocated & $\begin{array}{l}\text { Prensa, Panama } \\
\text { http://www.prensa.com/ }\end{array}$ \\
\hline
\end{tabular}

Viejo (Nicaragua), Area de Conservacion Guanacaste and Cocos Island National Park (Costa Rica), Parque Nacional La Amistad (Costa Rica and Panama), and Coiba National Park (Panama). Most of them are vulnerable to hydrometeorological phenomena from both the Caribbean and $\mathrm{Pa}-$ cific basins, such as cold fronts, easterly waves (e.g. the Belize Barrier Reef), and TCs impacts and intense precipitation from ITCZ (practically all of them). The WHS on the Pacific side of Central America located near steep slopes are susceptible to be impacted by intense precipitations and landslides due to the direct effect of TCs upon the Pacific basin and/or the indirect effect (high winds and induced topographic precipitation) from TCs over the Caribbean basin. The Diquis Delta site (see Fig. 1) is precisely located to the west of a region of steep slopes along the Talamanca Cordillera in southern Costa Rica and subject to heavy precipitations, landslides and associated erosion due to the latter effect. The following two studies are good examples of the vulnerability WHS and other cultural sites to environmental phenomena impacts. Salgado (2005), in his study about landslides and floods in the Gila River in Honduras reports that Hurricane Mitch (22 October-5 November 1998) seriously damaged the region of the Copan Ruins, a well known WHS in Honduras. More recently, Obando and Peraldo (2011) point out the importance of controlling by means of engineering work, the surface runoff, near the Guayabo National Monument in Costa Rica, to avoid the risk of damaging floods. Table 1 reveals some examples of environmental impacts on regional WHS during the period 2008-2012.

\subsection{A proposed site for WH: the Diquis Delta culture and the stone spheres}

According to Quintanilla and Badilla (2001), available information shows that the Diquis Delta in southern Costa Rica was barely populated until the beginning of XX century. In contrast, archeological data indicates that the area was the home of an important native culture between 800-1500 AC. This culture built diverse architectonic places for living, buried its deaths, erected public sculptures, and managed industries such as metallurgy, bone carving and the manufacture of stone and pottery artifacts. The above authors stressed the importance of the frequent floods over that region in the distribution pattern of archeological sites, so that these events forced the occupation, evacuation and possibly the reoccupation of the settlements. Quintanilla and Badilla (2001) bring the attention to one of the first reported floods in the history of Costa Rica. In 1552, Gil Gonzalez Davila, a Spanish explorer, traveled across southern Costa Rica and described his stay at a native settlement in the Diquis Delta. He accounted for a big flood that strongly affected this site. An important finding of Quintanilla and Badilla (2001) is that ancient floods may be responsible for the vertical distribution of archeological artifacts in the soil layers (from 0.7 to $2 \mathrm{~m}$. deep), some of which were dated as back as $1000 \mathrm{AC}$. A detailed description of the different soil layers found in archeological sites, including some of sedimentary origin, is also given by these authors. Among the most important archeological contributions of the Diquis Delta culture, are the stone spheres, some of which have diameters from 0.1 to $2.5 \mathrm{~m}$. (Quintanilla, 2007). This author also reports that more than 300 spheres were sculptured for public use by the Diquis Delta culture. Figure 2 shows one of the spheres of approximately $1.5 \mathrm{~m}$. in diameter located currently in "Finca 6", in southern Costa Rica. As can be noted, the stone appeared buried by a thick layer of soil and mood, presumably as a result of floods and erosion.

At this point, several questions emerge. To what extent may floods be the result of intense precipitation associated with TCs, either directly or indirectly induced? In regions 


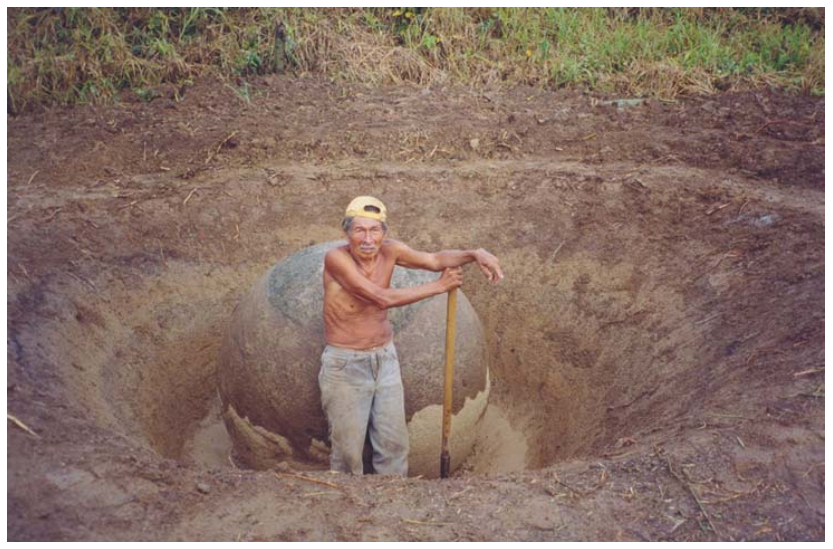

Fig. 2. Stone sphere of approximately $1.5 \mathrm{~m}$. in diameter located currently in Finca 6, in southern Costa Rica (courtesy of Costa Rica archeologist Ifigenia Quintanilla). Note the different soil layers around the sphere, presumably as a result of floods and erosion.

with scarce meteorological information, can numerical modeling help to improve time-space atmospheric data for decision making in regard to management and protection of cultural, social life and the WHS? An attempt to answer these questions is presented in the conclusions and recommendations section below.

\section{Data and methods}

\subsection{Climate data}

Data used to feed the atmospheric numerical model MM5 (see Sect. 3.3 below for an explanation of the model) are from the National Center for Environmental Prediction (NCEP) National Center for Atmospheric Research (NCAR) Reanalysis (described in detail by Kalnay et al., 1996). These data has a relatively course space resolution of about $250 \mathrm{~km}$ in all meteorological parameters used (e.g. wind, pressure, temperature, moisture, etc., at the surface and at different atmospheric levels). The time resolution for all variables is usually six hours for any given period. Although Reanalysis data is available all over the globe, its course space resolution of about $250 \mathrm{~km}$ in grid size makes impossible its use in local impact studies at the WHS level. Here is where the dynamical downscaling technique is of great utility (see Sect. 3.3 below). The NCEP-NCAR Reanalysis served then as input to the MM5 to obtain higher spatial resolution data to analyze at that level the potential meteorological impact of a tropical cyclone on the Diquis Delta region on southern Costa Rica. Cold fronts, easterly waves and tropical cyclones occurrences hitting Central America and having an impact in the region were considered as study objects. This information was analyzed for 2002-2012 and match with the press information to identify socio-economic impacts (see next section for information sources).

\subsection{Historical and socio-economic information sources}

For the study of regional impacts caused by natural hazards, public data bases like HURDAT (http://www.aoml.noaa.gov/ hrd/hurdat/newhurdat-format.pdf, last access: 21 July 2013) or EMDAT (http://www.emdat.be/, last access: 21 July 2013) were used. It is to be noted, however, that these data bases have two major limitations for local impact studies. First, the methodologies used and the institutions in charge to quantify the information, are sometimes different during its historical development; and second, some local events are not considered relevant for regional or basin scale, although some of them may be significant for local purposes. For the reasons mentioned above, this study reviewed information sources like national newspapers (e.g. La Nacion, www.nacion.com, last access: 21 July 2013) and, bulletins and documents produced by the regional National Meteorological Services in Central America to account for relevant climate events and their associated impacts in the region. Information from the regional National Emergency Committees that communicate, either via web sites or documents, socio-economic information associated with reported regional impacts, was also considered. In Costa Rica, data came from the National Meteorological Institute (http://www.imn.ac.cr/boletin_meteo/ historial\%20boletines.html, last access: 21 July 2013). As discussed in the earlier section of regional climate, systems are recurrent in Central America (but of course, of nonperiodic nature), so that past socio-economic damage due to these systems might be seen as an indicator of future risks to WHS, especially in regard to certain type of systems such as tropical cyclones.

\subsection{Methods}

Monthly meteorological bulletins, produced by the regional National Weather Services were revised from 2002 to 2012 and information related with potential weather and/or climate hazards that affected Central America was extracted This information was matched against the boreal winter cold front intrusions, to easterly waves travelling across the region, and to the activity of the two tropical cyclone regions (the Atlantic-Caribbean and the eastern tropical Pacific) during boreal summer-autumn. The documentation associated with one particular event was systematized in indices containing the start and end dates of the impact, the number of locations/regions affected, the sequence number of the event and the name in the case of TCs. After that, the information was bi-weekly and annually aggregated for analysis in time and then summarized. For Costa Rica an analysis in space, limited in few cases by poor press information, was also done to account for extreme rainfall events associated with the climate hazards mentioned above, considering that it is an important meteorological factor associated with the stone spheres degradation by weathering, landslides and erosion. The main categories used to aggregate the impacts 
include: floods, strong rains, landslides, tornado-like occurrences, atmospheric electricity, strong winds, infrastructure damage and deaths. These climate impacts can affect directly WHS infrastructure and surrounding social life and can destroy roads and bridges accessing WHS in vulnerable areas.

For the case study using the MM5 model, it is important to mention that southern Costa Rica, where the proposed WHS is located, has few meteorological stations to make a detailed analysis of meteorological variables for application to impact studies. Numerical modeling is an important tool that can be used to better understand weather and climate impacts in at least three ways. First, simulations can be used by forecasters to advice and help in the management of any possible emergency situations at any specific WHS. Second, it can also be used to fill missing information in space and time that is not available for the region, helping additionally in the attribution process of the information collected from different sources like press or radio broadcasting. Third, numerical models can be used, as is the case proposed in this work, to increase the space-time meteorological resolution in order to identify regions of extreme events in winds, precipitation, and other variables, to perform detailed studies and projections about socio-economic impacts near WHS locations. The process of using courser resolution atmospheric data such as that of NCEP/NCAR to obtain higher resolution information by the use of a numerical model is called dynamical downscaling. The study case presented here is about learning more about the atmospheric conditions leading to impacts due to TCs in southern Costa Rica (the site of the stone spheres). To achieve the above goal then, an atmospheric dynamic model (MM5) was run on a local computer cluster. The Pensylvania State University/NCAR mesoscale model (known as MM5) is a limited-area, nonhydrostatic, terrain-following sigma-coordinate model designed to simulate or predict mesoscale atmospheric circulation (see, http: //www.mmm.ucar.edu/mm5/. The MM5 used a basic configuration of 22 vertical sigma levels at four domains with spatial resolutions of $90,30,10$, and $3.3 \mathrm{~km}$, respectively. Physical options for the MM5 (Grell et al., 1995) model simulations include Grell's cumulus parameterization, the cloud radiation scheme (chosen to account for diurnal variations), and the Blackadar scheme for the planetary boundary layer. The model was initialized using NCEP/NCAR Reanalysis data (Kalnay et al. 1996) from 27 May 00Z to 30 May 06Z, 2008 to obtain higher resolution atmospheric data to make a more detailed meteorological analysis over the Diquis Delta region. The period used corresponds partly to the tropical depression that headed to the formation of tropical storm Alma upon the Pacific basin. Only data for the 27 May 2008 is shown here at the $3.3 \mathrm{~km}$ resolution domain to illustrate the severe atmospheric situation that caused abundant impacts in that region. A comparison with observed precipitation from a work by Stolz and Chinchilla (2008) is also made in order to assess MM5 results as a potential input for archeological site impact studies.
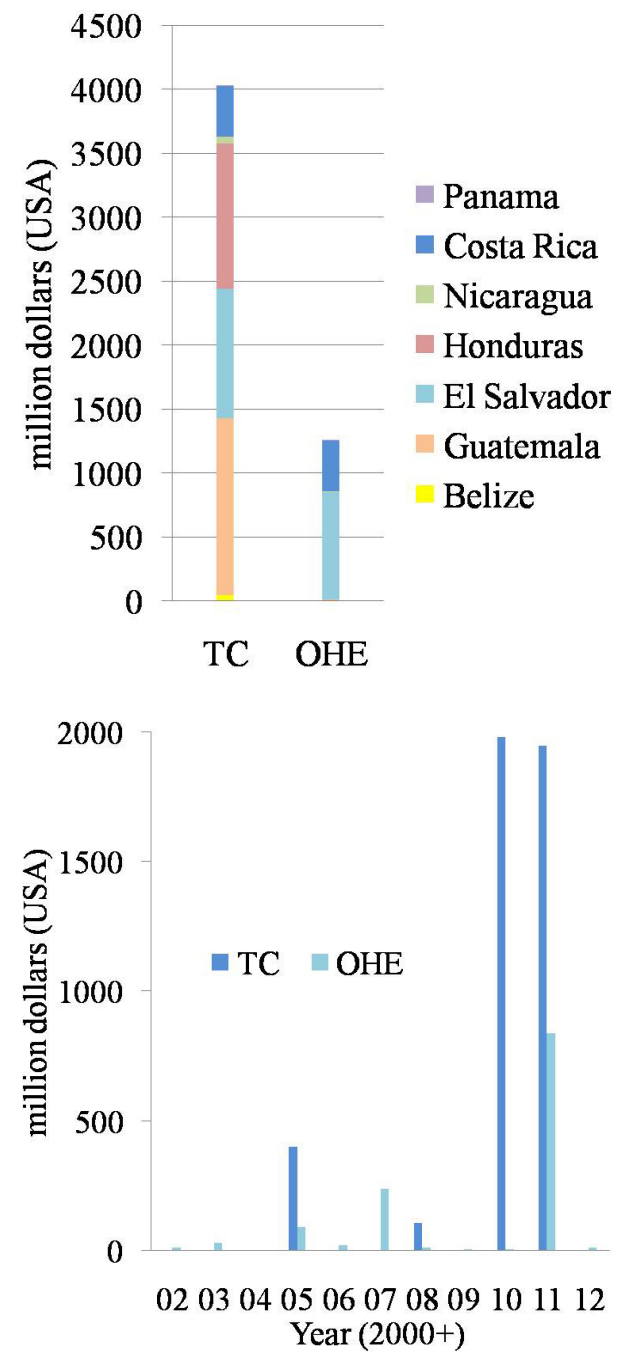

Fig. 3. (a) Loses in millions of \$USA per country in Central America due to tropical cyclone activity (TC) and other hydrometeorological events (OHE) and, (b) total loses in millions of \$USA per year in Central America due to TC and OHE during 2002-2012. Dollar amounts are for the years in which the event was recorded, so quantities are not corrected by inflation.

\section{Results}

\subsection{Regional impacts}

It was observed from all information sources that TCs were the hazards having more impacts in both, losses in terms of millions of dollars of the United States of America (\$USA) and deaths in Central America (Figs. 3 and 4, respectively), when compared with other hydro-meteorological events during the period 2002-2012. Note however, that years having a great impact in losses as 2010 and 2011 (Fig. 3) do not necessarily correspond with years of great impacts in terms of deaths as 2005 (Fig. 4). Notice that deaths could be used as a variable associated with the magnitude of the impact which 

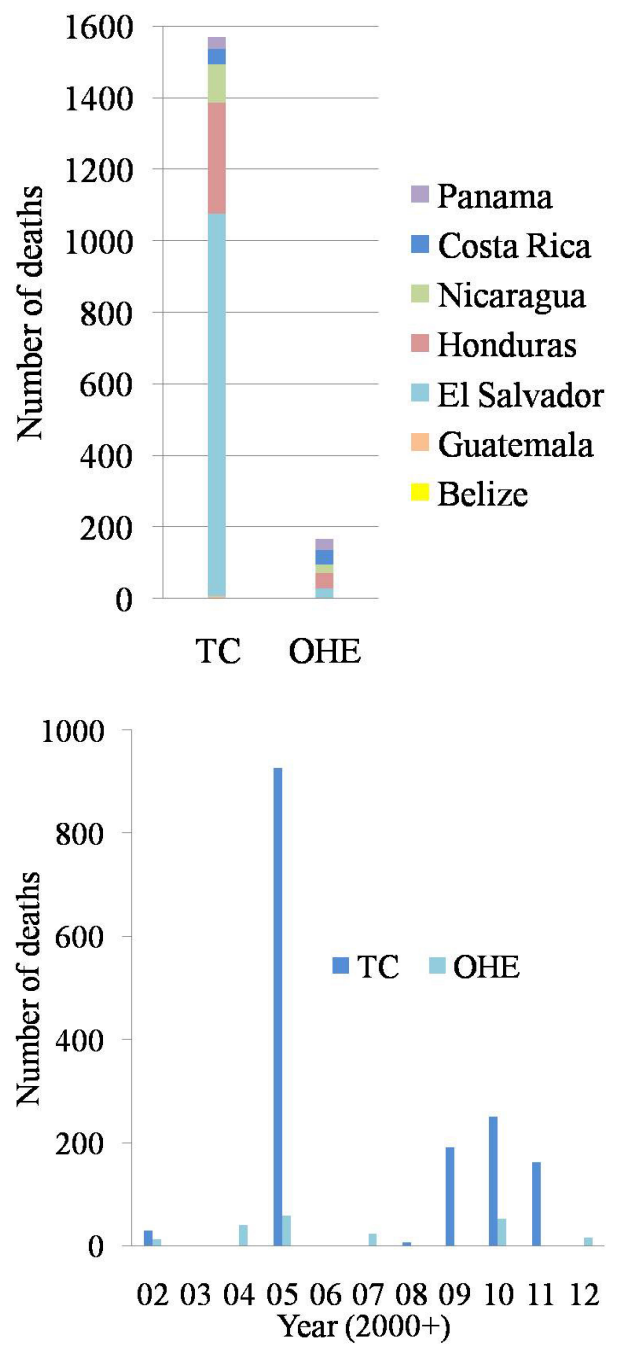

Fig. 4. (a) Number of victims per country due to tropical cyclone activity (TC) and other hydro-meteorological events (OHE) and, (b) number of victims per year due TC and OHE during 2002-2012.

in turn can be related to the degree of emergency attendance in a WHS.

The main impact from all variables analyzed was due to heavy rainfall events of convective origin. TCs are the main flood producers, associated with the so-called "indirect effect" of a low pressure system located either in the CS or the ETP, on the Central America Pacific slope (Peña and Douglas, 2002). Those impacts are mainly concentrated from May to October, with 2010 as the year that concentrated the main quantity of impacts from the analyzed record. This could be associated with the dipole configuration of warmer tropical Atlantic and colder eastern equatorial Pacific around the isthmus during most of the 2010 rainy season, especially during its second peak. This dipole configuration has been shown to favor a more active rainy season on the Pacific slope of Central America (Enfield and Alfaro, 1999; Maldonado et al., 2013). Cold fronts have a smaller quantity of impacts on the South Pacific in 2002-2012 when compared with the other two hazards, and are mainly associated with strong winds. Reviewing the press information, 13 of these events were widely covered by media confirming that TCs and easterly waves are the main sources of atmospheric impacts (Table 2). Of special interest was the year of 2005 that also presented a peak in the Atlantic basin due to TCs activity.

When the impact information from southern Costa Rica Pacific is compared with other regions in the country, it was observed that Central Valley concentrates the main quantity. This region hosts most of the Costa Rica population with the higher level of exposition and vulnerability to hydro-meteorological hazards. This means that other socioeconomic variables should be included to explain high impact values in the Central Valley. This result agrees with the analysis presented by Alfaro et al. (2010), Alfaro and Quesada (2010) and Maldonado et al. (2013).

\subsection{The Diquis Delta region in southern Costa Rica}

As a study case, a tropical cyclone (main climate hazard identified for the region) was simulated using a mesoscale numerical model. Results for the MM5 runs are shown in Fig. 5. The large scale flow with a resolution of $30 \mathrm{~km}$ associated with the position of the storm is illustrated in Fig. 5a, the corresponding precipitation is shown in Fig. 5b. The tropical depression induced an intense low-level wind that converged at the base of the Talamanca mountain range in southern Costa Rica (observed at the $3.3 \mathrm{~km}$ resolution domain at $925 \mathrm{hPa}$ in Fig. 5c). Heavy accumulated precipitation associated with this tropical depression is observed in the model output for the period 27 May from 06:00-18:00 LT (local time) (Fig. 5d). The purple solid line in Fig. 5c and d, illustrates the approximate region of the Diquis Delta archeological site. Notice that the information presented in Fig. 5 can be used to fill missing information in space and time for the case of regions where data from meteorological station network stations is not available for any specific WHS. This approach helps in the attribution process of the information collected from different sources like press, television and radio broadcasting. The convective activity and associated precipitation was intense and long lasting causing serious effects on population and infrastructure (see Table 2). Figure 1 shows the location of the places mentioned in Table 2. According to the National Meteorological Institute (Stolz and Chinchilla, 2008), the Pacific slope of Costa Rica registered the main impacts, in terms of accumulated precipitation in Costa Rica during 28-29 May, however rainfall was also important on the 27 May. The average recorded rainfall by automatic meteorological stations for 28 May were for North Pacific $69 \mathrm{~mm}$, central Pacific $146 \mathrm{~mm}$, south Pacific $94 \mathrm{~mm}$, Central Valley $59 \mathrm{~mm}$, northern region $77 \mathrm{~mm}$ and Caribbean $1.6 \mathrm{~mm}$. The average values for 29 May were for north Pacific $47 \mathrm{~mm}$, central Pacific $179 \mathrm{~mm}$, south Pacific $83 \mathrm{~mm}$, Central Valley 
Table 2. Socio-economic impacts due to hydro-meteorological activity during the period 2002-2012 in the south Pacific slope of Costa Rica according to press reports.

\begin{tabular}{|c|c|c|c|c|}
\hline $\begin{array}{l}\text { Date } \\
(\mathrm{dd} / \mathrm{mm} / \mathrm{yyyy})\end{array}$ & $\begin{array}{l}\text { Towns and } \\
\text { cities affected }\end{array}$ & $\begin{array}{l}\text { Socio-economic } \\
\text { impacts }\end{array}$ & $\begin{array}{l}\text { Sources of } \\
\text { information }\end{array}$ & $\begin{array}{l}\text { Atmospheric } \\
\text { system }\end{array}$ \\
\hline 23 Oct 2004 & $\begin{array}{l}\text { Isla Violín, } \\
\text { Puerto Jiménez, } \\
\text { Golfito }\end{array}$ & $\begin{array}{l}\text { Three deaths, water } \\
\text { and electricity cuts, } \\
\text { landslides, more than } \\
100 \text { damaged houses }\end{array}$ & $\begin{array}{l}\text { NEC, CRRC, } \\
\text { PF, La Nación }\end{array}$ & Tropical wave and ITCZ \\
\hline 18 Jul 2005 & $\begin{array}{l}\text { La Gamba, } \\
\text { La Viquilla, } \\
\text { La Julieta }\end{array}$ & $\begin{array}{l}\text { One injured, } \\
5 \text { collapsed bridges, } \\
50 \text { damaged houses }\end{array}$ & $\begin{array}{l}\text { NEC, NMI, } \\
\text { La Nación }\end{array}$ & Hurricane Emily (indirect effect) \\
\hline 17 Nov 2005 & $\begin{array}{l}\text { San Vito de } \\
\text { Coto Brus- } \\
\text { Ciudad Neily, } \\
\text { Río Claro- } \\
\text { Golfito y Río } \\
\text { Claro-Palma } \\
\text { Sur }\end{array}$ & $\begin{array}{l}\text { More than } 300 \text { people } \\
\text { evacuated, } 1200 \text { in } \\
\text { shelters, water cuts, } \\
\text { severe damage in rice } \\
\text { and banana plantations }\end{array}$ & $\begin{array}{l}\text { Golfito and } \\
\text { Corredores' } \\
\text { LEC, PF, } \\
\text { La Nación }\end{array}$ & \multirow{2}{*}{ Tropical Storm Gamma } \\
\hline 20 Nov 2005 & $\begin{array}{l}\text { Corredores, } \\
\text { Golfito }\end{array}$ & $\begin{array}{l}17 \text { public schools } \\
\text { closed, } 516 \text { damaged } \\
\text { houses, } 600 \text { people in } \\
\text { shelters }\end{array}$ & $\begin{array}{l}\text { SSI, NEC, } \\
\text { La Nación }\end{array}$ & \\
\hline 26 Nov 2005 & $\begin{array}{l}\text { Potrero Grande } \\
\text { y Golfito }\end{array}$ & $\begin{array}{l}\text { One bridge collapsed, } \\
15 \text { damaged houses }\end{array}$ & NEC, La Nación & Cold front intrusion 23 Nov 2005 \\
\hline 28 May 2008 & $\begin{array}{l}\text { Cobano, Parrita, } \\
\text { Lepanto, } \\
\text { Paquera }\end{array}$ & $\begin{array}{l}\text { Two deaths, one } \\
\text { person missing, } 65 \\
\text { injured, water and } \\
\text { electricity damages, } \\
866 \text { people in } \\
\text { shelters, } 139 \\
\text { damaged bridges, } \\
\text { houses and public } \\
\text { schools with } \\
\text { damages, } \\
\text { approximately } \\
\text { USD } 40 \text { million }\end{array}$ & $\begin{array}{l}\text { NEC, NMI, } \\
\text { La Nación }\end{array}$ & Tropical storm Alma \\
\hline 19 Oct 2008 & $\begin{array}{l}\text { Paso Canoas, } \\
\text { Corredores }\end{array}$ & $\begin{array}{l}\text { Damaged houses and } \\
\text { civil establishments }\end{array}$ & PF, NMI & Tropical Depresion 16 \\
\hline 1 Nov 2009 & Golfito & 10 damaged houses & $\begin{array}{l}\text { PF, NEC, NMI, } \\
\text { La Nación }\end{array}$ & Tropical Depresion 11 \\
\hline $25 \mathrm{Jul} 2010$ & $\begin{array}{l}\text { Golfito, } \\
\text { Corredores }\end{array}$ & 10 damaged houses & $\begin{array}{l}\text { PF, NMI, } \\
\text { La Nación }\end{array}$ & Tropical wave 28 \\
\hline 21 Aug 2010 & $\begin{array}{l}\text { Corredores y } \\
\text { Golfito }\end{array}$ & $\begin{array}{l}\text { One person missing, } \\
20 \text { families in } \\
\text { shelters, several } \\
\text { damaged houses }\end{array}$ & $\begin{array}{l}\text { Golfito LEC, } \\
\text { CRRC, NMI, } \\
\text { La Nación }\end{array}$ & Tropical wave 37 \\
\hline 23 Oct 2011 & $\begin{array}{l}\text { Osa, Golfito, } \\
\text { Corredores }\end{array}$ & 135 people in shelters & $\begin{array}{l}\text { NEC, NMI, } \\
\text { CRRC, Firemen, } \\
\text { PF, La Nación }\end{array}$ & Low pressure system and ITCZ \\
\hline 16 Oct 2012 & $\begin{array}{l}\text { Parrita, Quepos, } \\
\text { Palmar Norte, } \\
\text { Buenos Aires }\end{array}$ & Landslides & $\begin{array}{l}\text { NMI, PF, La } \\
\text { Nación }\end{array}$ & \multirow{2}{*}{ Tropical storms Sandy and Tony } \\
\hline 23 Oct 2012 & Zona Sur & Landslides & $\begin{array}{l}\text { NEC, NMI, } \\
\text { La Nación }\end{array}$ & \\
\hline
\end{tabular}



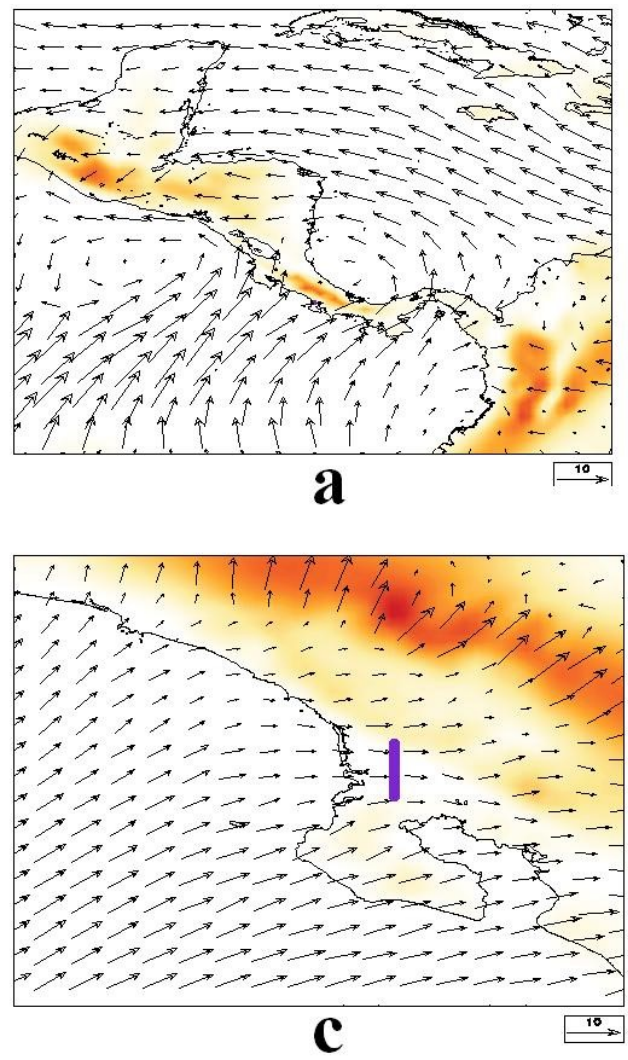

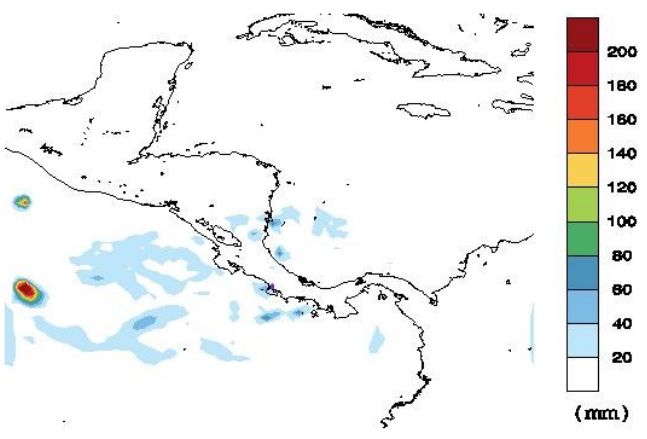

b

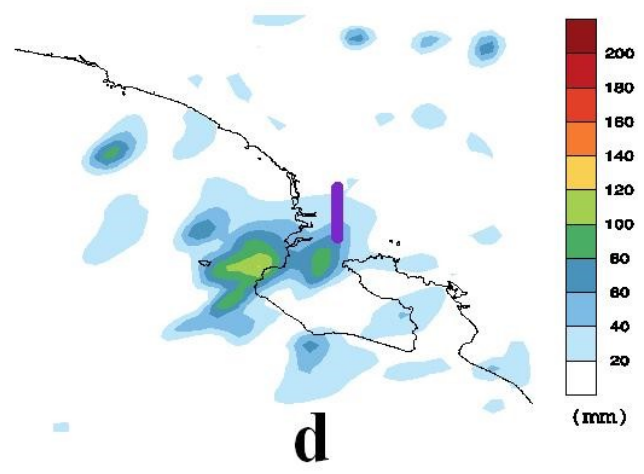

Fig. 5. MM5 mean simulations for 27 May 2008 from 06-18Z of tropical depression that conducted to the formation of tropical storm Alma for (a) wind vector at $925 \mathrm{hPa}$ at a domain with a resolution of $30 \mathrm{~km}$; (b) accumulated precipitation at a domain with a resolution of $30 \mathrm{~km}$; (c) same as (a) but for a domain of $3.3 \mathrm{~km}$ resolution; and (d) same as (b) but for a domain with of $3.3 \mathrm{~km}$ resolution. The purple vertical solid line in (c) and (d) denotes the region near the Diquis Delta in southern Costa Rica, home of the archeological site of the stone spheres.

$88 \mathrm{~mm}$, northern region $69 \mathrm{~mm}$ and the Caribbean with less than $1 \mathrm{~mm}$.

\section{Conclusions and future work}

Central America is home of several very important WHS for its culture and nature. Most of the WHS are localized in areas of extreme events such as high winds, intense precipitation, landslides, and floods, among other natural hazards. The study of the meteorological systems associated with those events is crucial to understand not only local environmental phenomena and its likely causes but to account for and help in the prevention of similar situations causing relevant socio-economic impacts. This type of work is also useful in helping governments and institutions, dealing with conservation and promotion of cultural and natural sites, in the amelioration and prevention of impacts that may put at risk WHS. The geographical location and topographical characteristics of the Central America Isthmus in the IAS defines most of its climate and its climate variability, so the study of these signals is fundamental for socio-economic life in the region. Among the climate hazards that affect the world heritage places of Central America is the boreal winter cold front intrusions. During summer-autumn the region is also affected by easterly waves and by the activity of two tropical cyclone regions, the Atlantic-Caribbean and the eastern tropical Pacific. Historical and press data were used to construct a set of socio-economic impacts due to the above systems during the period 2002-2012. The economic impacts of TCs over Central America during the period analyzed were very high (Fig. 3a and b) for the already weak regional economies putting at risk many of the World Heritage Sites. The number of casualties due to TC impacts during the last decade was also dramatically elevated (Fig. 4a and b). Additionally to this, Central America has about 31 new proposals to UNESCO for World Heritage, tangible and intangible, as the Archaeological Site of Stone Spheres in the Diquis Delta in the south Pacific region of Costa Rica. Easterly waves and tropical cyclones are the systems with more hydro-meteorological effects in the south Pacific region in Costa Rica for 20022012. The main impact is trough heavy rainfall events, but TCs are the main flood producers, mainly concentrated from May to October (Table 2). Cold fronts have a smaller impact number on the south Pacific, most of them associated with strong winds. 
The dynamical downscaling technique used here with the MM5 provided high resolution $(3.3 \mathrm{~km}$ grid size atmospheric data) from meteorological information derived from the NCEP-NCAR Reanalysis originally at a courser resolution of about $250 \mathrm{~km}$ of grid size. Results for the MM5 runs showed that the tropical depression (later tropical storm Alma) induced an intense low-level wind that converged at the base of the Talamanca mountain range in southern Costa Rica, a rich archeological site, home of the stone spheres, artifacts built by the Diquis Delta culture. This intense precipitation was associated is associated via official and press information with landslides, floods and the consequent erosion processes along rivers and planes in southern Costa Rica. The observed convective activity and associated precipitation was intense and long lasting causing serious effects on population and infrastructure. As a consequence of this, the Pacific slope of Costa Rica registered the main impacts, in terms of accumulated precipitation, in Costa Rica during 27-29 May 2008.

The model runs did not capture well the observed precipitation along the rest of the period of analysis. It is suggested that perhaps the NCEP/NCAR data may be drier than the actual atmosphere, so the MM5 could not dynamically downscale the variables to obtain the registered precipitation patterns. Also, for relatively weak storms, such as that of a tropical depression stage, the reanalysis data may be too course to produce the correct forcing on the MM5 to reproduce observed atmospheric quantities. In this case, it as has been pointed out before (Amador et al., 2012), the intensity of the storm may not be as important as the closeness of the storm to the vulnerable area. Intense rainfall during relatively short periods of time (6-12 h) associated with climate hazards such as those mentioned above is an important meteorological factor that may be also associated with the stone spheres site degradation by weathering, landslides and erosion. The latter process can cover parts of this proposed WHS with abundant mud so that for this partially undisclosed archeological site such the identification and exploration work may be even more difficult and costly.

This work has identified very important socio-economic effects caused by several meteorological systems hitting Central America during the period 2002-2012. Many of these impacts are located in areas of relevance to WHS management and protection. Mesoscale numerical modeling is also an important tool to derive atmospheric data at a higher resolution than that available in most types of reanalysis of atmospheric data. The derived information can then be used for local impact studies, especially in areas where there is a lack of observed atmospheric data. Since this work has only analyzed a limited amount of meteorological systems in a relatively general way, future work on impacts of a wider range of systems and meteorological conditions on specific regional WHS should be considered.
Acknowledgements. The authors wish to acknowledge the support of the following projects: IAI-CRN2-050, UCR-VI-805-B0-065, A8-606, B0-130, A9-224, A7-002, B0-402, B3-600 and 808A9-180. Special thanks go to Costa Rica archeologist Ifigenia Quintanilla for discussions and suggestions on the Diquis Delta culture, and for kindly providing image for Fig. 2. Blanca Calderon and Fernan Saenz kindly helped with the MM5 runs and figures. Thanks also to Ingrid Rivera, Carla Vega, Elsie Troyo, Carlos Bojorge for data processing, and to Paula Perez for her support with figure cartography. Anonymous reviewers made valuable criticisms to improve the clarity, structure and content of this work.

Edited by: K. Tokeshi

Reviewed by: D. J. Rohde and two anonymous referees

\section{References}

Alfaro, E.: Response of Air Surface Temperatures over Central America to Oceanic Climate Variability Indices, Tópicos Meteorológicos y Oceanográficos, 7, 63-72, 2000.

Alfaro, E.: Some Characteristics of the Annual Precipitation Cycle in Central America and their Relationships with its Surrounding Tropical Oceans, Tópicos Meteorológicos y Oceanográficos, 9, 88-103, 2002.

Alfaro, E. and Quesada A.: Ocurrencia de ciclones tropicales en el Mar Caribe y sus impactos sobre Centroamérica, Revista Intersedes, 11, 136-153, 2010.

Alfaro, E., Quesada, A., and Solano, F.: Análisis del impacto en Costa Rica de los ciclones tropicales ocurridos en el Mar Caribe desde 1968 al 2007, Revista Diálogos, 11, 22-38, 2010.

Amador, J. A.: A climatic feature of the tropical Americas: The trade wind easterly jet, Tópicos Meteorológicos y Oceanográficos., 5, 91-102, 1998.

Amador, J. A.: The Intra-Americas Seas Low-Level Jet (IALLJ): Overview and Future Research, in: Ann. N. Y. Aacad. Sci. Trends and Directions in Climate Research, edited by: Gimeno, L., Garcia, R., and Trigo, R., 1146, 153-188, 2008.

Amador, J. A.: Socio-economic impacts associated with meteorological systems and tropical cyclones in Central America in 2010, [In State of the Climate 2010], B. Am. Meteorol. Soc., 92, S184, 2011.

Amador, J. A., Chacon, R. E., and Laporte, S.: Climate and climate variability in the Arenal Basin of Costa Rica, in: Climate and Water: Transboundary Challenges in the Americas, edited by: Diaz, H. F. and Morehouse, B., Klewer Academic Publishers BV, The Netherlands, 317-350, 2003.

Amador, J. A., Alfaro, E. J., Lizano, O. G., and Magaña, V. O.: Atmospheric forcing of the eastern tropical Pacific: A review, Prog. Oceanogr., 69, 101-142, 2006.

Amador, J. A., Alfaro, E. J., Rivera, E. R., and Calderón, B.: Climatic features and their relationship with tropical cyclones over the Intra- Americas Seas, in: Hurricanes and Climate Change, edited by: Elsner, J. B., Hodges, R. E., Malmstadt, J. C., and Scheitlin, K. N., Springer, Dordrecht, Heidelberg, London, New York, p. 255, 2010. 
Amador, J. A., Hidalgo, H. G., Alfaro, E. J., Calderón, B., Mora, N. P., and Rivera, I. L.: [Regional Climate] Central America [in "State of the Climate in 2012"], B. Am. Meteorol. Soc., 93, S169-S170, 2012.

Enfield, D. and Alfaro, E.: The dependence of Caribbean rainfall on the interaction of the tropical Atlantic and Pacific Ocean, J. Climate, 12, 2093-2103, 1999.

Gray, W. M.: Hurricane: Their formation, structure and likely role in the tropical circulation, in: Meteorology over Tropical Oceans, edited by: Shaw, D. B., Royal Meteorological Society, James Glaisher House, Grenville Place, Bracknell, Berkshire, 155-218, 1979.

Grell, G. A., Dudhia, J., and Stauffer, D. R.: A description of the fifth-generation Penn State/NCAR mesoscale model (MM5), NCAR Technical Note, NCAR/TN-398+STR, available from NCAR publications office, Boulder, CO, p. 138, 1995.

Hastenrath, S.: Climate Dynamics of the Tropics, Kluwer Academic Publishers, Dordrecht, 488 pp., 1991.

Hidalgo, H. G., Amador, J. A., Alfaro, E. J., and Quesada, B.: Hydrological Climate Change Projections for Central America, J. Hydrol., 495, 94-112, doi:10.1016/j.jhydrol.2013.05.004, 2013.

Kalnay, E., Kanamitsu, M., Kistler, R., Collins, W., Deaven, D., Gandin, L., Iredell, M., Saha, S., White, G., Woollen, J., Zhu, Y., Chelliah, M., Ebisuzaki, W., Higgins, W., Janowiak, J., Mo, K. C., Ropelewski, C., Wang, J., Leetmaa, A., Reynolds, R., Jenne, R., and Joseph, D.: The NCEP/NCAR Reanalysis 40-year Project, B. Am. Meteorol. Soc., 77, 437-471, 1996.

Magaña, V., Amador, J., and Medina, S.: The mid-summer drought over Mexico and Central America, J. Climate, 12, 1577-1588, 1999.

Maldonado, T., Alfaro, E., Fallas-López, B., and Alvarado, L.: Seasonal prediction of extreme precipitation events and frequency of rainy days over Costa Rica, Central America, using Canonical Correlation Analysis, Adv. Geosci., 33, 41-52, doi:10.5194/adgeo-33-41-2013, 2013.
Obando, L. G. and Peraldo, G.: Geo-arqueología del Monumento Nacional Guayabo (MNG), Turrialba, Costa Rica. Rev. Geol. Amér. Central, 44, 119-130, 2011.

Peña, M. and Douglas, M. W.: Characteristics of Wet and Dry Spells over the Pacific Side of Central America during the Rainy Season, Mon. Weather Rev., 130, 3054-3073, 2002.

Quintanilla, I.: Esferas precolombinas de Costa Rica/PreColumbian Spheres of Costa Rica, Fundación Museos del Banco Central de Costa Rica, San José, 2007.

Quintanilla, I. and Badilla, A.: El impacto de los fenómenos naturales sobre los yacimientos arqueológicos de la llanura aluvial del Delta del Diquis, Costa Rica, Revista Vínculos, 26, 57-77, 2001.

Salgado, R. A.: Análisis integral del riesgo a deslizamientos e inundaciones en la microcuenca del Río Gila, Copán, Honduras, Tesis Magister Scientiae, CATIE, Turrialba, Costa Rica, 2005.

Stolz, W. and Chinchilla, G.: Informe especial. Tormenta Tropical Alma y sus efectos en Costa Rica (28 y 29 de mayo de 2008), in: Boletín Meteorológico Mensual, Instituto Meteorológico Nacional, Ministerio de Ambiente, Energía y Telecomunicaciones, San José, Costa Rica, 17-26, 2008.

Taylor, M. and Alfaro, E.: Climate of Central America and the Caribbean, in: Encyclopedia of World Climatology, edited by: Oliver, J. E., Springer, the Netherlands, 183-189, 2005.

Wang, C. and Enfield, D.: The tropical western hemisphere warm pool. Geophys. Res. Lett., 28, 1635-1638, 2001.

Wang, C. and Enfield, D. B.: A further study of the tropical Western Hemisphere warm pool, J. Climate, 16, 1476-1493, 2003. 